\title{
MONODOCÊNCIA EM ANGOLA: entre tensões e controvérsias no ensino primário
}

Francisco Caloia Alfredo

Resumo

Este artigo tem por objetivo discutir a atual monodocência no ensino primário, implementada na última reforma educativa em Angola, em 2004. Trata-se de um regime unificado de seis anos para o ensino primário, onde apenas um professor leciona a todas as disciplinas curriculares da 1 . $^{\mathrm{a}}$ à 6 . $^{\mathrm{a}}$ classe. Numa abordagem qualitativa, essencialmente descritiva, analisa-se este regime da monodocência nas duas Leis de Bases, nos documentos oficiais, em articulação com as falas dos professores do ensino primário. A legislação expressa orientações e estabelece um conjunto de competências de que se esperam desenvolvidas nos alunos do ensino primário, tal como os documentos que terminam contrariados com os argumentos dos professores no terreno. Quando analisados estes elementos, percebe-se que a monodocência de seis anos gera controvérsias e bastante contestada entre os atores da educação porque não apresenta resultados evidentes, por falta, essencialmente, de preparação dos professores e de condições adequadas de trabalho para atividade docente.

Palavras-chave: monodocência; ensino primário; formação, reforma educativa.

MONOTEACHING IN ANGOLA: among tensions and contraversies in the primary teaching

\section{Abstract}

This article discussees the current monoteaching primary school teaching system implemented during the last educational restructure in 2004 through a unified system of six (6) grades to be covered in six schooling years with a teacher deliver all the school subjects. In the descriptive qualitative research, the monoteaching system is analysed based on two basic laws in the official papers linked to the primary school teachers views. The legislation provides guidelines and establishes a set of expected skills to be developed by the learners in this education system as well as the rejected theories of the acting teachers in the field. After analyzing the study results it has been concluded that the monoteaching sytem generated controversies and huge contests amongst the teachers in the system because of the ineffective outcomes, lack of qualified trained personnel and appropriate working and teaching conditions.

Keywords: monoteaching; primary school system; training; educational restructuring.

MONODOCENCIA EN ANGOLA: entre tensiones e controversias en la enseñanza primaria

Resumen

Este artículo tiene por objetivo discutir la actual monodocencia en la enseñanza primaria, implementada en la última reforma educativa en Angola, en 2004. Se trata de un régimen unificado de seis años para la enseñanza primaria, donde apenas un profesor enseña todas las disciplinas curriculares desde $1 .^{\circ}$ a $6 .^{\circ}$ grado. En un abordaje cualitativo, esencialmente descritivo, se analisa este régimen de la monodocencia en las dos Leyes de Bases, en los documentos oficiales, en articulación con las opiniones de los profesores de enseñanza primaria. La legislación expresa orientaciones y establece el conjunto de competencias que se esperan desarrollar en los alunos de enseñanza primaria, que terminan contrariados con los argumentos de los profesores. Quando se analisan estos elementos, se percibe que la monodocencia de seis años viene 
generando polémicas entre los actores de la educación porque no presenta resultados evidentes, por falta de preparación de los profesores y de condiciones adecuadas de trabajo para la actividad docente.

Palabras clave: monodocencia; enseñanza primaria; formación, reforma educativa.

\section{INTRODUÇÃO}

Há mais de quinze anos, o sistema educativo em Angola conheceu a segunda reforma educativa no pós independência do país, que, apesar de haver ainda poucos estudos e discussões sobre a mesma, alguns autores angolanos a analisam nos seus variados aspetos, do ponto vista da sua finalidade e contexto das políticas educativas (ALFREDO, 2018; NGABA, 2012; NGULUVE, 2010; MENEZES, 2009), nos aspetos relativos ao currículo e formação de professores (BAXE, FERNANDO e PAXE, 2016; AFONSO, 2015; TAVARES, 2015; ALFREDO e TORTELLA, 2014; BENEDITO, 2014; QUITEMBO, 2014), sobre o direito à educação (PAXE, 2014; FRANCISCO, 2013) e ainda relativo à avaliação das aprendizagens (ALFREDO, 2014; ALFREDO e TORTELLA, 2013, 2012).

Geralmente, as reformas educativas justificam a introdução de transformações para a melhoria dos sistemas educativos (LIMA e AFONSO, 2002; POPKEWITZ, 1997; PACHECO, 2000; VIDAL e ASCOLANI, 2009). Tendo, com isso, se admitido no sistema educativo angolano haver lacunas originárias da anterior reforma a esta, assim como se ter percebido a necessidade de se adequar o sistema educativo vigente às atuais exigências da educação (ALFREDO, 2018). Dessa reforma educativa ocorreram mudanças no sistema educativo, tal é a introdução, no subsistema do ensino geral, da monodocência que, à luz da Lei de Bases do Sistema Educativo (LBSE)-Lei n. ${ }^{\circ}$ 13/01, sobre a qual repousa a referida reforma, constitui um regime do ensino primário unificado de 6 (seis) anos, onde um professor leciona a todas as disciplinas curriculares da 1 . $^{\mathrm{a}}$ à $6 .{ }^{\mathrm{a}}$ classe. Sendo, portanto, 9 (nove) nomeadamente as disciplinas de Língua Portuguesa, Matemática, Ciências Integradas, Educação Musical (Canto, Teatro e Dança), Formação Manual e Politécnica, Educação Física, Educação Visual e Plástica, Educação Moral e Cívica, e Ciências da Natureza.

Não estando os professores preparados para lecionarem o conjunto das disciplinas curriculares propostas na monodocência de seis anos nas distintas áreas (BAXE, FERNANDO e PAXE, 2016), acrescida da falta de condições de trabalho, a implementação da monodocência vem consagrando, na educação básica, baixa qualidade no ensino angolano. Note-se que ao longo dos mais de quinze anos de reforma educativa, esse regime de ensino vem sendo bastante contestado pelos atores da educação, gerando tensões e controvérsias (CEIC, 2012).

Estando nesse sentido a motivação da pesquisa realizada relacionada com o fato de ainda existir em Angola pouca produção, reflexões e debates académicos sobre a (mono)docência e outras áreas, sem, com isso, descurar que haja, gradualmente, tendências de algum crescimento da produção científica. Assim, o objetivo do presente artigo é o de analisar as tensões, os desafios e as controvérsias em torno da monodocência de 6 (seis) anos, considerando a interface entre a legislação, notas sobre a reforma educativa e os discursos dos professores do ensino primário no terreno. Com uma abordagem qualitativa, essencialmente descritiva, não menos analítica, além de se discorrer sobre os normativos, na altura disponíveis, e analisar outros documentos, também se analisa os discursos dos professores participantes da pesquisa, manifestos da aplicação de questionário e entrevista, nos quais se assinalam os aspetos fundamentais relativos ao regime de monodocência de 6 (seis) anos.

\section{REFORMA EDUCATIVA EM ANGOLA: ALGUMAS NOTAS}


Quando em 2002 Angola registava o início da estabilidade política, ocorreram transformações sociais no país, como na educação o surgimento da segunda reforma educativa implementada em 2004. A implementação dessa reforma ocorreu mediante um cronograma: a fase de preparação (2000-2012), serviu para a criação das condições para o funcionamento das instituições de ensino, podendo nessa fase, entre outros aspetos, "elaborarem-se novos currículos (perfis de saída, planos de estudo, programa de ensino e materiais pedagógicos, bem com a sua reprodução e distribuição", “[...] formação do pessoal docente e dos gestores escolares", "aquisição de meios de ensino e equipamentos pelas instituições escolares, e reabilitação de infraestruturas escolares" (INIDE, 2009, p. 13). Apesar dessa fase da reforma ter elencado um conjunto de atividades, as mesmas foram debilmente conseguidas, inclusive as consideradas essenciais, tal foi a "formação de pessoal docente e gestores escolares manifestamente [...] insuficiente" e "a aquisição de meios de ensino e de equipamentos escolares e a construção e reabilitação de estabelecimentos de ensino também ficou aquém do desejável" (MENEZES, 2009, p. 60). Seguiu-se a fase da experimentação (2004-2010), que consistiu na introdução do novo material pedagógico nas escolas do país, seguida da fase de avaliação e correção (2005-2012), marcada pela observação e análise da aplicação desse material pedagógico. À medida que se procurava concretizar essas fases da reforma educativa, quer esta última quer a outra fase, vinha à tona a real imagem do país, a exemplo, da "inexistência de sala de aula (nas zonas rurais muitas das aulas são ministradas debaixo de árvores) ou salas com 50 a 90 alunos, muito distante dos 35 preconizados na reforma educativa [...]”, "a falta de motivação de diretores, professores e inspetores devido aos baixos salários e aos problemas de enquadramento, bem como, a ausência de condições de trabalho", "a fraca comparticipação dos pais e encarregados de educação na aquisição dos materiais pedagógicos essencialmente por razões financeiras" e "o número insuficiente de manuais distribuídos às escolas e a inexistência dos mesmos nas escolas apesar destas estarem a implementar a reforma” (MENEZES, 2009, p. 62). Decorrida esta fase, o cronograma previa a fase da generalização (2006-2011), incidindo na extensão global da reforma, com a aplicação dos novos currículos, ao que se seguiu a fase da avaliação global, prevista para 2012 (INIDE, 2009). Paralelamente às atividades realizadas pelo Ministério da Educação (MED), estudos, como o realizado por Menezes (2009) refere que os objetivos manifestos na reforma educativa não foram devidamente conseguidos porque, entre outras razões, "não estão a ser organizados os programas especiais de aperfeiçoamento e reciclagem em número desejável para docentes sem habilitação profissional", "não se faz sentir o programa de reabilitação e construção de escolas, nem de mobiliário escolar, nem a distribuição de merenda escolar" (MENEZES, 2009, pp. 59-60). Este autor ainda refere que "as mudanças nos planos curriculares no sentido de promover a interdisciplinaridade e outros aspetos pedagógicos pouco ou nada foram implementados nas escolas por falta de recursos nas organizações escolares e devido à falta de formação adequada e atempada dos professores experimentados, os recursos das escolas, a distribuição gratuita dos manuais escolares, dos programas e dos instrumentos de avaliação (caderneta e relatório) por todas as escolas primárias", "houve pouca ou nenhuma preparação com a motivação dos professores porque apesar do professor ser o protagonista de qualquer inovação curricular, porquanto, compete a ele realizar o currículo e promover a interação das componentes socioeducativas, curriculares e didáticas [...] o professor enquanto agente curricular não foi ouvido nem motivado no âmbito da reforma educativa [...]” (ibidem, p. 64).

Diante deste panorama, pode melhor entender-se os processos sobre os quais foi introduzida a monodocência de 6 (seis) na reforma educativa em questão.

\section{MONO-DOCÊNCIA: ENTRE TENSÕES E CONTROVÉRSIAS}


A última reforma educativa ao ampliar o ensino primário para o regime de monodocência de 6 (seis) anos, na altura, referia-se que atendia a "uma necessidade qualitativa, assegurando a satisfação das necessidades educativas fundamentais das crianças com idade escolar" (ANGOLA, 2001, p. 52). Tendo o Ministério da Educação (MED) considerado a ampliação deste regime de ensino de monodocência de 6 (seis) anos sem constrangimento de grande relevo, pois

a) A transferência de algumas disciplinas que outrora pertenciam ao I Nível e que no novo sistema iniciam na 5. ${ }^{a}$ classe, tais como História, Geografia, Ciências da Natureza e Educação Musical, cuja antiga carga horaria da 1. à 4. classe, partilhou-se equitativamente para todas as classes de Ensino Primário a razão de 1 hora por semana;

b) As disciplinas de Matemática, Língua Portuguesa e Educação Física cujos antigos conteúdos eram leccionados durante quatro anos, são leccionados agora durante seis anos com algumas inovações (MED, 2012, s/p) ${ }^{1}$.

Não sendo esses fatores únicos, parece terem sido minimizadas as condicionantes relativas ao número de aluno por turma, às condições de trabalho e às longas distâncias que muitas vezes os professores e alunos têm de percorrer para chegarem à escola. Decerto, constituem fatores com implicações no sucesso da monodocência.

Apesar da unificação do ensino primário a uma monodocência de 6 (seis) anos, e essa unificação fazer a cobertura de 78\% das escolas públicas pelo país (CEIC, 2012), ela tem gerado tensões e controvérsias. Portanto, a monodocência de seis anos tem sido "bastante contestada e não tem dado resultados, por evidente falta de preparação do corpo docente" (CEIC, 2012, p. 89). Embora se lhe reconheça em si, como escreve Filipe Zau, razões de caráter psicopedagógico que, geralmente, encerra uma monodocência, "tal como as metodologias de aprendizagem que estão em consonância com a psicologia do desenvolvimento e a psicologia das idades" (ZAU, 2012, p. 168).

Do ponto de vista da Lei de Bases do Sistema Educativo Angolano - Lei n. ${ }^{\circ}$ 13/01 (lei que introduziu a monodocência em questão), ao conformar o ensino primário no regime de monodocência de 6 (seis) anos, pretendeu-se a) "desenvolver e aperfeiçoar o domínio da comunicação e da expressão", b) "aperfeiçoar hábitos e atitudes tendentes à socialização", c) "proporcionar conhecimentos e capacidades de desenvolvimento das faculdades mentais", d) "estimular o espírito estético com vista ao desenvolvimento da criação artística" e e) "garantir a prática sistemática de educação física e de actividades gimnodesportivas para o aperfeiçoamento das habilidades psico-motoras" (LBSE, ARTIGO 18. ). No domínio da formação de professores do ensino primário, o objetivo é a formação de professores com perfis compatíveis à plena materialização dos objetivos da educação, detentores de conhecimentos e em constante atualização e aperfeiçoamento (ARTIGO 27..$^{\circ}$ ), estando, no entanto, definida a formação de professores em nível médio (ARTIGO 29..$^{\circ}$.

Dezasseis anos depois, revogou-se a referida Lei de Bases, tendo surgido uma nova Lei de Bases do Sistema Educativo e Ensino (LBSEE) - Lei n. ${ }^{\circ}$ 17/16 que apesar de organizar o ensino primário por ciclos de aprendizagem e, globalmente, redefinir os objetivos deste subsistema do ensino geral, consolida o regime de ensino de monodocência de 6 (seis) anos. Estando assim o ensino primário organizado por 3 (três) ciclos de aprendizagem constituídos por 2 (duas) classes por ciclo. O primeiro ciclo compreende a 1. ${ }^{a}$ classe (classe de transição automática) e a 2. ${ }^{a}$ classe

\footnotetext{
1 Refere-se no plano de estudos do novo sistema de educação que no ensino primário, as disciplinas de Matemática Língua Portuguesa são a que registaram maior aumento da carga horaria. Tendo a Língua Portuguesa da $1 .^{\mathrm{a}}$ à $4 .^{\mathrm{a}}$ classe 9 horas semanais, e a $5 .^{\mathrm{a}}$ e $6 .^{\mathrm{a}}$ classe 8 horas semanais. A Matemática, da $1 .^{\mathrm{a}}$ à $4 .^{\mathrm{a}}$ classe 7 horas semanais, e a $5 .^{\mathrm{a}}$ e $6 .^{\mathrm{a}}$ classe 6 horas semanais (MED, 2012).
} 
(classe de avaliação final do ciclo), o segundo ciclo compreende a $3 .^{a}$ classe (classe de transição automática) e a $4{ }^{a}$ classe (classe de avaliação final dos objetivos do ciclo) e, por fim, o terceiro ciclo com a 5. ${ }^{a}$ classe (de transição automática) e a $6{ }^{a}$ classe (de avaliação do ciclo) (LBSEE, ARTIGO 29. ${ }^{\circ}$.

Tal como referido atrás, decorrente do alargamento do ensino primário em regime de monodocência de 6 (seis) anos, muitas são as dificuldades dos professores em lidar com esse regime de ensino, por falta de preparação dos professores para lecionar neste mesmo regime de monodocência, desarticulação dos currículos entre a formação dos professores (entre o nível médio e superior) e a prática da atividade docente, falta de condições de trabalho, de infraestruturas adequadas de ensino, e desmotivação com a remuneração direta e indireta dos professores. A estes elementos ainda se associa o elevado número de aluno por turma, situação também central no que a aprendizagem de todos os alunos com sucesso diz respeito (ALFREDO, 2014). Este cenário revela ser uma miragem à consecução dos objetivos do ensino primário definidos na nova Lei de Bases que, à guisa exemplificativo, alude para o ensino primário a necessidade do domínio da escrita, da leitura, do cálculo, do desenvolvimento das competências de comunicação e da expressão escrita e oral (LBSEE, ARTIGO 29. ${ }^{\circ}$ ). Ainda se sugere a formação de professores para o exercício da atividade docente no ensino primário, cursos de formação média em escolas de Magistério, com a possibilidade dessa formação docente ocorrer nas escolas superiores de formação de professores ou nas escolas pedagógicas (ibidem, ARTIGO 46. $.^{\circ}, 47 .^{\circ}, 49 . .^{\circ}$ ).

Talvez com o intuito de mitigar as evidências do insucesso da monodocência de 6 (seis) anos, recentemente surge a Lei n. ${ }^{\circ} 32 / 20$, que introduz alterações na vigente Lei de Bases. Contendo, entre outras alterações, a redução da monodocência para 4 (quatro) anos, colocando assim o regime de monodocência da 1. ${ }^{\mathrm{a}}$ à $4 .^{\mathrm{a}}$ classe. Recorde-se, com esta alteração do regime de monodocência, voltou-se assim ao regime que já vigorou no sistema educativo angolano, na primeira reforma educativa do pós independência de Angola.

Sendo esta última lei muito recente e não tendo havido (por altura da redação do presente artigo), outros elementos que pudessem confluir para a sua análise no âmbito da monodocência de quatro classes, a mesma não constituiu assunto de análise. Ainda assim, admito que a alteração do regime de monodocência resulta das sucessivas pressões sobre o agravamento da qualidade do ensino primário em Angola e dos descontentamentos dos principais atores educativos, como se aborda mais à frente.

Olhando para a relação entre a monodocência de 6 (seis) anos e a distribuição de escolas de formação de professores em Angola, poder-se-á compreender e confirmar que a falta de professores e a adequada formação dos mesmos constituem handicap para o sucesso deste regime de ensino. Veja-se, por exemplo, sobre a rede de escolas de formação de professores.

\section{Redes de escolas de formação de professores}

Se, por um lado, se acredita haver o esforço para a formação de professores para atender às necessidades do ensino primário e não só, por outro lado, e não menos verdade, as dificuldades com o regime de monodocência de 6 (seis) anos colocam em relevo a carência de professores devidamente formados, assim como o tardio surgimento e expansão das escolas de formação de professores, como ilustra a tabela 1 . Ou seja, começou-se por introduzir na reforma educativa um ensino primário unificado de 6 (seis) anos sem que houvesse escolas de formação especializadas para professores. 
Tabela 1 : Rede de escolas de magistério primário em Angola

\begin{tabular}{|l|c|c|}
\hline N. ${ }^{\circ}$ de escolas & Ano de 2012 & Ano de 2017 \\
\cline { 2 - 3 } Públicas & 23 & 20 \\
\hline Comparticipadas & 3 & 23 \\
\hline Total & 26 & 43 \\
\hline
\end{tabular}

Fonte: MED (2017a)

Embora os anos expressos na tabela 1 referem que o número de escolas públicas de formação de professores pelo país seja (num dado momento) superior ao número de escolas comparticipadas, notou-se descontinuidade no crescimento do número dessas escolas entre os dois anos expressos. Outro aspeto, tem que ver com o número de escolas de formação de professores distribuídas pelo país num dado período, conforme mostra a tabela infra.

Tabela 2: Rede de escolas de formação de professores por província

\begin{tabular}{|l|c|c|c|c|}
\hline \multirow{3}{*}{$\begin{array}{c}\text { PROVÍNCIAS DE } \\
\text { ANGOLA }\end{array}$} & \multicolumn{3}{|c|}{ MAGISTÉRIO PRIMÁRIO } \\
\cline { 2 - 3 } Bengo & \multicolumn{2}{|c|}{ Comparticipado } & \multirow{2}{*}{ Público } & \multirow{2}{*}{ Total } \\
\cline { 2 - 3 } & ADPP2 & Outro & & 1 \\
\hline Benguela & 1 & --- & --- & 4 \\
\hline Bié & 1 & 2 & 4 & 4 \\
\hline Cabinda & 1 & --- & 3 & 1 \\
\hline Cuando Cubango & 1 & --- & --- & 1 \\
\hline Cuanza Norte & 1 & --- & --- & 1 \\
\hline Cuanza Sul & 1 & --- & --- & 7 \\
\hline Cunene & 1 & --- & 6 & 1 \\
\hline Huambo & 1 & --- & --- & 2 \\
\hline Huíla & 2 & 2 & 1 & 3 \\
\hline Luanda & --- & 1 & 1 & 2 \\
\hline Lunda Norte & 1 & 1 & 1 & 3 \\
\hline Lunda Sul & --- & --- & 1 & 1 \\
\hline Malanje & 1 & --- & 2 & 3 \\
\hline Moxico & 1 & 1 & --- & 2 \\
\hline Namibe & --- & 1 & --- & 1 \\
\hline Uíge & --- & --- & 1 & 1 \\
\hline Zaire & 1 & --- & --- & 1 \\
\hline & 1 & --- & --- & 1 \\
\hline
\end{tabular}

Fonte: MED (2017b)

É de notar que, além da cobertura desproporcionada do número de escolas de formação de professores pelo país (talvez por razões de concentração demográfica ou históricas), a tabela 2 ainda mostra a inexistência de escolas de formação de professores nas 18 (dezoito) províncias de Angola. E não sendo prioritário o investimento na educação desse país, e a continuar-se com os

\footnotetext{
2 A ADPP (Ajuda de Desenvolvimento de Povo para Povo) é um dos projetos de uma ONG norueguesa voltado para a educação - neste caso particular focada para a formação de professores para o futuro nas zonas rurais - desenvolve também projetos na saúde, desenvolvimento rural e económico, na agricultura e meio ambiente.
} 
baixos investimentos do Estado para a educação, como, de resto, vem se registando ao longo destes anos (ALFREDO, 2014; 2018; OPSA e ADRA, 2012; 2014; 2015), menos provavelmente se poderá alterar o cenário atual da educação, do ensino e da formação com qualidade a altura das exigências dos tempos.

\section{PROCEDIMENTOS METODOLÓGICOS}

Tratou-se de um estudo, essencialmente, descritivo (não menos analítico), onde se descrevem os fatos, as situações ou processos que ocorrem (SOUSA e BATISTA, 2011; AFONSO, 2014) cujo foco é o de conhecer a realidade (TRIVIÑOS, 2010). Os dados analisados constituem recorte de um estudo amplo, tendo para o presente texto dados de professores de 4 (quatro) escolas do ensino primário do Lubango, cidade capital da província da Huíla. Constitui-se assim uma amostra de 38 (trinta e oito) professores, dos quais um diretor pedagógico. Destes professores, 31 (trinta e um) são de duas escolas do ensino primário que responderam ao questionário de perguntas fechadas, do qual se ressaltou aspetos relativos à monodocência. Dos respondentes do questionário, 4 (quatro) professores são do sexo masculino e 27 (vinte e sete) do sexo feminino. Os dados do questionário foram completados com os da entrevista semi-estruturada (PARDAL e LOPES, 2011) aplicada a 7 (sete) professores de duas escolas também do ensino primário. Procedeu-se a uma análise triangulada. Os professores entrevistados estão identificados com as letras do alfabeto (exemplo, professor A, B, C...).

\section{DADOS EMPÍRICOS SOBRE A MONODOCÊNCIA}

Neste ponto, analisam-se e discutem-se os dados obtidos da aplicação de questionários e das falas dos professores do ensino primário participantes do estudo. Estes professores, sobretudo os entrevistados, quando questionados sobre a monodocência não só se referiam à mesma em si, também se referiam aos processos da sua implementação no âmbito da reforma educativa, sobre a qual repousa este regime de ensino de 6 (seis) classes. Assim, começando por caraterizar o nível de escolaridade e o tipo de formação obtida, dos 31 (trinta e um) professores do ensino primário, 23 (vinte e três) responderam ter formação de professor entre o ensino médio e superior (graduação) e 8 (oito) responderam não ter qualquer formação de professores. Tal indicador sinaliza não existir exigência (rigor) na seleção de professores para o ensino primário, como que para se tornar professor em Angola bastaria ter qualquer que seja a formação. Aliás, apesar de se estabelecer o perfil do professor (DECRETO n. ${ }^{\circ}$ 3/08 de 4 de março; ALFREDO e TORTELLA, 2014) ainda assim os professores podem ser classificados em categorias de professor e de agente da educação (DECRETO PRESIDENCIAL n. ${ }^{\circ}$ 109/11). Note-se que as respostas dos professores participantes do estudo confirmam que a formação de professor de que ostentam a nível médio ou superior, não os preparou efetivamente para lecionar no regime de monodocência de 6 (seis) anos. Portanto, os mesmos professores tiveram formações nas escolas de formação média e superior público e privado de professores sem, necessariamente, se formarem para atender ao regime de ensino de monodocência de 6 (seis) anos. Além do mais, verificou-se que o nível de escolaridade desses professores é essencialmente médio, ou seja 21 (vinte e um) professores que responderam ao questionário têm formação média, 2 (dois) são bacharéis, 7 (sete) licenciados/graduados e 1 (um) sem resposta. Assim, a questão com a monodocência de 6 (seis) anos prende-se com o fato de não ter havido professores devidamente formados para o efeito, o que sugere a existência de precipitação com a sua implementação. E como se viu nas tabelas 1 e 2 , a formação para professores do ensino primário foi tardia em relação à implementação da monodocência. Nessa 
direção, uma das professoras entrevistas é enfática ao referir que "[...] primeiro, tinha que se formar professores e depois aplicar a monodocência. $\mathrm{Na}$ minha humilde opinião, penso que fizeram o contrário. Começou-se a trabalhar na monodocência com professores de especialidade, e isso trouxe alguns constrangimentos" (professora C).

[...] eles implementaram a reforma mas antes não capacitaram os professores para poderem trabalhar com a reforma. $\mathrm{Na}$ minha singela opinião, antes da implementação da reforma devia se ver o quadro do pessoal [com] que vai trabalhar com essa reforma (professora E).

Quando questionados se a monodocência constitui avanço no melhoramento da qualidade do ensino, como era de esperar, a maior parte dos professores participantes do estudo, 58\% (18 professores), respondeu desfavoravelmente, $23 \%$ (7 professores) respondeu favoravelmente a essa pergunta do questionário, $3 \%$ (1 professor) indeciso e 16\% (5 professores) não responderam a essa questão.

Note-se que além da falta de professores adequados para a monodocência, também se coloca a questão das condições de trabalho, como diz uma das professoras entrevistadas "Penso que primeiro tinha que se investir nas estruturas, tinha que se construir mais escolas, ampliar talvez algumas e também empregar mais professores para que se possa trabalhar de facto com os alunos que nós temos que formar" (professora C).

As falas dos professores no terreno da escola mostram que foram produzidos normativos na contramão da realidade das escolas. Ou seja,

[...] infelizmente a realidade mostra outra coisa. Nos normativos tudo bem, tudo escrito que a reforma educativa está correr bem, é um sucesso. [...] o grande problema está nas duas últimas classes $\left(5 .^{a}\right.$ e $6 .^{a}$ classes). Os professores têm muitas dificuldades de ensinar as nove disciplinas porque ali os conteúdos de matemática e língua portuguesa precisam mesmo de especialistas. Nem todo professor está preparado para lidar com a matemática da $6 .^{a}$ classe. As dificuldades começam logo com a $4{ }^{a}$ classe, há professores que têm dificuldades. $\mathrm{Na}$ conversa que eu tenho tido com os professores que lecionam essas classes, eles têm tido coragem de informar que senhor diretor, eu coisa que não sei não posso mentir aos alunos, deixo de parte. Então os professores dão os temas que entendem e às vezes deixa de parte os conteúdos essenciais. O professor só está aí para cumprir, mas não para ensinar, assim não se espera bons resultados. [...] a monodocência é um grande problema. $\mathrm{Na}$ minha opinião pessoal, gostaria que

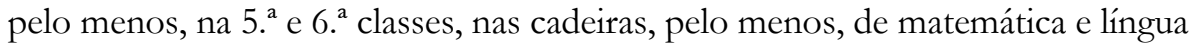
portuguesa houvesse mesmo professores especializados para lecionar estas disciplinas. Mesmo nas escolas de formação de professores, o profissional só é especializado em duas disciplinas. No IMNE se é matemática faz matemática e física, se for química faz biologia e química, a português [...] é só uma disciplina de especialização, a inglês é uma, a francês uma só. Então, quando este professor é colocado no ensino primário, apesar de antes da especialização fazer uma formação geral, esta nem sempre é suficiente devido a parte metodológica, devido a tal especificidade de cada disciplina. O professor pode ser bom numa área, mas noutra não é bom. A título de exemplo, nós temos, em relação a essas novas cadeiras que foram introduzidas no currículo, a educação musical é um grande problema, os professores não conseguem dar aulas de educação musical porque o IMNE, assim como o ISCED não têm curso de educação musical. [...] 
os professores [...] se dão aulas de educação musical e educação física muitas vezes é de forma empírica (professor F - diretor pedagógico de escola).

Do ponto de vista da prática da atividade dos professores do ensino primário, há quem também indica que, por um lado, "há também coisas importantes na reforma, por exemplo na iniciação o aluno já escreve, dantes a iniciação era só cantar. Agora faz-se tudo” (professora A). Assim como a avaliação contínua dos alunos. Tal como referia aquele diretor pedagógico, pode haver boas intenções da reforma educativa ou com a monodocência. Porém, estas intenções se afrouxam num conjunto de condicionalismos, como os já atrás assinalados e apontadas por uma professora da $6{ }^{a}$ classe com seis anos de professorado e membro do conselho de direção da sua escola.

A reforma cria muitas dificuldades aos professores. Vamos ser sinceros, por exemplo no caso da monodocência até à $6 .^{a}$ classe, eu vou ser sincera que tenho dificuldades porque há disciplinas que posso até dar de uma maneira teórica, mas quando for na prática já não é bem como devia ser. É o caso das disciplinas de educação musical, educação física, educação manual e plástica, que necessitam de aprofundamento, por exemplo as disciplinas de matemática e língua portuguesa (professora D).

Uma outra professora, com seis anos de professorado, assinala o fato de existir nas salas de aula um

[...] número excessivo de aluno por turma. Por exemplo, nesta minha turma da $5{ }^{a}$ classe, como nós sabemos estamos na monodocência, é uma dificuldade. Hoje, por exemplo, consta no horário três disciplinas: língua portuguesa, matemática e história. Nem sempre o professor consegue gerir o tempo [...]. Outro caso da reforma educativa é a transição automática (professora E).

O desconforto dos professores em relação ao elevado número de alunos por turma (nas classes de monodocência) é partilhado por todos eles. Aliás, e na senda do que escrevem muitos autores (ZABALA, 1998; IBERNÓN, 2011; BOLÍVAR, 2012; CANDAU, 2008; LIBÂNEO, 1990, entre outros), do ponto de vista pedagógico essa realidade é bastante questionável, e até inadmissível em muitos contextos educativos.

Os dados empíricos são incisivos ao confirmarem o elevado número de alunos por turma. As turmas apresentam não só um elevado número de alunos, como também os números de que dispõem essas turmas não se uniformizam. Note-se que 9 (nove) professores participantes da pesquisa (da 1. à $6 .^{a}$ classe) têm entre 36 e 40 alunos por turma, 7 (sete) professores têm entre 41 e 45 alunos, igualmente 7 (sete) professores têm até 35 alunos, 3 (três) professores têm entre 46 e 50 alunos, 2 (dois) professores têm entre 51 e 55, igualmente 2 (dois) professores têm entre 56 e 60 alunos por turma. Articulados os dados às falas dos professores entrevistados, há quem refere, tal é como uma professora da classe da Iniciação, que "[...] há turmas com 55 alunos ou mesmo 60 alunos, [...] há escolas com turma de 70 alunos. A professora não consegue transmitir a matéria porque há muito barulho, há muita desorganização e fica difícil” (professora B). A angústia dessa professora é corroborada por uma outra com 23 anos de professorado, que diz "[...] é muito aluno na sala. Acredito que se fosse o número indicado para essas alterações que foram feitas, acredito que muita coisa acontecia" (professora C). Quanto ao mais, diz ainda aquela professora da Iniciação, "trabalhar com todas as disciplinas é muito cansativo para um professor, porque nem todos estão aptos a lecionar todas as disciplinas [...] o professor é obrigado a trabalhar com todas as disciplinas. São muitos alunos, há turmas com mais de 50 alunos” (professora C). E como que 
aflita, uma outra professora, com 27 anos de magistério, na altura, refere que "[...] a monodocência cria, criou e está a criar dificuldades principalmente nas provas e mesmo no trabalho que dá" (professora A). Nessa linha, argumenta uma outra professora, com 28 anos de magistério, na altura, apontando as dificuldades para atingir os objetivos do ensino primário apregoados na Lei de Bases do Sistema Educativo e Ensino. Referindo-se à transição automática nas 1. a , 3. a 5. $^{\mathrm{a}}$ classes deplora:

O aluno sabendo ler, escrever ou não tem que aprovar para a classe seguinte. [...] o aluno chega numa classe de exame, já não consegue avançar porque ele não teve bases suficientes para poder estar naquela classe. O aluno devia reprovar, sim. Não sabe ler, não sabe escrever o próprio nome, não consegue tirar um conteúdo do quadro para o caderno (professora $G$ ).

Quando questionados os professores no item: todos os meus alunos são capazes de alcançar os objetivos minimos de cada disciplina, as respostas, embora haja mais professores discordando 13 (treze) professores, 2 (dois) professores sem opinião formada e 12 (doze) professores concordando, tendem a revelar um equilíbrio entre estes respondentes no sentido de haver um esforço para que os alunos alcancem o mínimo cultural. Outro aspeto referido no âmbito da monodocência tem a ver com a falta de material para os alunos.

“[...] uma das dificuldades da monodocência é o material escolar. Nas escolas públicas nem todos os encarregados têm condições para adquirir material escolar, e também as nossas escolas nem sempre fornecem o material escolar. Por exemplo, um aluno da $4 .^{\mathrm{a}}$ classe, que é classe de exame, que não tem livro de língua portuguesa dificulta muito"(professora $\mathrm{E}$ ).

Quanto ao mais, a falta de uma adequada acomodação dos alunos, em sala de aula, pode retirar-lhes a atenção à aula, a concentração e dificultar as aprendizagens. E no contexto das escolas de Angola, da cidade do Lubango em particular, ainda "há alunos que escrevem sentados nas cadeirinhas/banquinhos, há os que sentam nas latas de leite e apoiam o caderno sobre as pernas, isso dificulta muito" (professora E). É, de fato, óbvia a falta de salas de aula adequadas no centro urbano, como a realidade da professora da Iniciação que diz "Pelo que vê aqui na classe da iniciação estamos a trabalhar fora ao relento, não há condições. Ao ar livre é mesmo difícil, os alunos se distraem não prestam atenção na aula, tal como você tem a oportunidade de ver" (professora B).

As transformações no atual ensino primário, e não só, em Angola podem positivamente ocorrer, sobretudo na sala de aula, se conformadas com o que diz uma professora: "o número de aluno (se) for reduzido e melhorar as condições de trabalho a coisa funciona" (professora C). Tal, também demanda atribuir-se mais atenção à educação, melhorando os investimentos do Estado neste sector.

\section{CONSIDERAÇÕES FINAIS}

Pretendeu-se refletir em torno da monodocência de 6 (seis) anos, implementada na última reforma educativa em Angola. Num contexto em que, fundamentalmente, a falta de preparação adequada de professores e da criação de condições para a atividade docente não foram suficientemente tidos em consideração. Com efeito, essa monodocência gerou controvérsias e bastante contestada pelos atores da educação, mormente os professores, porque não tem produzido resultados evidentes.

Os normativos expressam orientações e sinalizam um conjunto de competências que deviam ser adquiridas pelos alunos nesse regime de ensino, como se compreende as intenções do 
ministério de tutela de mitigação das fragilidades da monodocência. Porém, quando se aproxima à realidade das escolas e às práticas dos professores, apesar do esforço destes últimos, estas são atravessadas de entraves que protelam a promoção do ensino e das aprendizagens de forma satisfatória e com sucesso dos alunos. Os professores não têm preparação adequada para lecionar a todas a disciplinas curriculares da monodocência, além de se depararem com turmas com elevado número de alunos, escolas e salas de aulas sem as mais dignas condições para a atividade docente. Portanto, a panóplia destas situações coloca na contramão o que as diretrizes apregoam para o melhoramento do sistema educativo e de ensino, o que parece ser mais um conjunto de boas intenções.

Com o surgimento da Lei n. ${ }^{\circ} 32 / 20$, que altera a monodocência vigente para 4 (quatro) anos e apesar disso, haja, provavelmente, menos sufoco aos professores, sobretudo, do ensino primário. Todavia, essa alteração surge numa altura em que ainda são evidentes a exígua formação de professores à altura das necessidades do sistema educativo nacional, a falta de condições adequadas de trabalho para os professores, o registo de elevado número de aluno por turma e, ainda, o protelamento do investimento do Estado na Educação.

\section{REFERÊNCIAS}

ALFREDO, Francisco C. Avaliação das aprendizagens: política, concepções e práticas na formação de professores em Angola. Rio de Janeiro: Outras Letras, 2014.

ALFREDO, Francisco C. Políticas educativas e avaliação das aprendizagens: discursos e práticas de professores. Tese de doutorado em educação. Doutorado em política educativa, Universidade do Minho, Portugal - Braga, 2018.

ALFREDO, Francisco C.; TORTELLA, Jussara C. Avaliação da aprendizagem: concepções e prática na formação de professores em Angola. Revista Estudo em Avaliação Educacional, São Paulo, v. 24, n. ${ }^{\circ}$ 55, pp. 246-271, abr./ago., 2013.

ALFREDO, Francisco C.; TORTELLA, Jussara C. Avaliação da aprendizagem na formação de professores em Angola. Revista Roteiro, Joaçaba, v. 37, n. o 2, pp. 191-201, jul./dez., 2012.

ALFREDO, Francisco C. ; TORTELLA, Jussara C. Formação de professores em Angola: o perfil do professor do ensino básico. Revista Eccos, São Paulo, n. ${ }^{\circ} 33$, pp. 125 -142, jan./abr., 2014.

AFONSO, Augusto E. Re)construção do currículo: o papel do professor. Benguela: Ondjiri, 2015.

AFONSO, Natércio. Investigação naturalista em educação: um guia prático e crítico. Gaia: Fundação Manuel Leão, 2014.

ASCOLANI, Adrián; VIDAL, Diana G. (orgs.). Reformas educativas no Brasil e na Argentina: ensinos de história comparada da educação (1820-2000). São Paulo: Cortez, 2009.

ANGOLA. Decreto n..$^{\circ}$ /08, de 4 de março de 2008, I Série - n. ${ }^{\circ} 40$. Aprova o Estatuto Orgânico da Carreira dos Docentes do Ensino Primário e Secundário, Técnicos Pedagógicos e Especialistas 
de Administração da Educação. Diário da República, Órgão Oficial da República de Angola, Luanda, 4 mar. 2008.

ANGOLA. Lei n. ${ }^{\circ}$ 13/01, de 31 de dezembro de 2001, I Série - n. ${ }^{\circ}$ 65. Lei de Bases do Sistema de Educação. Diário da República, Órgão Oficial da República de Angola, Luanda.

ANGOLA. Lei n. ${ }^{\circ}$ 17/16, de 7 de outubro de 2016, I Série - n. ${ }^{\circ} 170$. Lei de Bases do Sistema de Educação e Ensino. Diário da República. Órgão Oficial da República de Angola, Luanda.

ANGOLA. Lei n. ${ }^{\circ}$ 32/20, de 12 de agosto de 2020, altera a Lei n. ${ }^{\circ}$ 17/16, de 7 de outubro de 2016, I Série n. ${ }^{\circ}$ 123. Lei de bases do Sistema de Educação e Ensino. Diário da República. Órgão Oficial da República de Angola, Luanda.

ANGOLA. Decreto Presidencial n. ${ }^{\circ}$ 109/11, de 26 de maio de 2011, I Série, n. ${ }^{\circ} 98$. Aprova o estatuto do subsistema de formação de professores. Diário da República, Luanda.

BAXE, Helena; PAXE, Isaac; FERNANDO, Mbiavanga. Ensino Primário em Angola, actuação e identidade dos professores. Luanda: Rede Angola da sociedade Civil para Todos, 2016

BENEDITO, Narciso D. Reforma educativa: um olhar sobre a melhoria da qualidade do ensino e da formação. In MORGADO, José C.; QUITEMBO, Alberto D. (orgs.). Currículo, avaliação e inovação em Angola: perspectivas e desafios. Benguela: Ondjiri, 2014, pp. 13-43.

BOLÍVAR, António. Melhorar os processos e os resultados educativos: o que nos ensina a investigação. Vila Nova de Gaia: Fundação Manuel Leão, 2012.

CANDAU, Vera M. Rumo a uma nova didática . Petrópolis, RJ: Vozes, 2008.

CENTRO DE ESTUDO E INVESTIGAÇÃO CIENTÍFICA (CEIC). Relatório social de Angola. Luanda: Universidade Católica de Angola, 2012.

FRANCISCO, Roberto G. O direito à educação básica em Angola: desafios e problemas à luz do direito internacional dos direitos humanos. Dissertação de mestrado em direitos humanos. Mestre em Ciências Jurídicas, Universidade Federal da Paraíba, Paraíba, 2013.

IMBERNÓN, Francisco. Escola, formação de professores e qualidade do ensino. Pinhais: editora Melo, 2011.

INSTITUTO NACIONAL DE INVESTIGAÇÃO E DESENVOLVIMENTO DA EDUCAÇÃO (INIDE). Informação sobre a implementação do novo sistema de educação: reforma educativa no ensino primário e secundário. Luanda, 2009.

LIBÂNEO, José C. Didática. São Paulo: Cortez, 1990.

LIMA, Licínio C. ; AFONSO, Almerindo J. Reformas da educação pública: democratização, modernização, neoliberalismo. Porto: Afrontamento, 2002.

MENEZES, Manuel A. Estudo de caso sobre a Reforma Educativa. Luanda, 2009. Disponível em: www.adra-angola.org (acesso em 18 de mar. 2014).

MINISTÉRIO DA EDUCAÇÃO DE ANGOLA (MED). Plano Nacional de Desenvolvimento 20132017 (documento policopiado), Luanda, 2012.

MINISTÉRIO DA EDUCAÇÃO DE ANGOLA (MED). Relatório de balanço das principais actividades realizadas no quinquénio 2012 - 2017, 2017 a.

MINISTÉRIO DA EDUCAÇÃO DE ANGOLA (MED). Reestruturação da formação de professores e avaliação das instituições de formação de professores, 2017b.

NGABA, André V. Politicas educativas em Angola 1975-2005: entre o global e o local, o sistema educativo mundial. Mbanza Kongo: Sedieca, 2012. 
NGULUVE, Alberto K. Educação angolana: políticas de reformas do sistema educacional. Piracicaba, São Paulo: Biscalchin, 2010.

OBSERVATÓRIO POLÍTICO E SOCIAL DE ANGOLA e AÇÃO PARA O DESENVOLVIMENTO RURAL E AMBIENTE (OPSA e ADRA). Posição sobre o Orçamento Geral do Estado. Luanda, 2015.

OBSERVATÓRIO POLÍTICO E SOCIAL DE ANGOLA e AÇÃO PARA O DESENVOLVIMENTO RURAL E AMBIENTE (OPSA e ADRA). Posição sobre o Orçamento Geral do Estado. Luanda, 2014.

OBSERVATÓRIO POLÍTICO E SOCIAL DE ANGOLA e AÇÃO PARA O DESENVOLVIMENTO RURAL E AMBIENTE (OPSA e ADRA). Análise preliminar do OGE 2012. Luanda, 2012.

PAXE, Isaac P. Políticas educacionais em Angola: desafios do direito à educação. Tese de doutorado em educação. Doutorado na área de sociedade e educação, Universidade de São Paulo, São Paulo, 2014.

PARDAL, Luís; LOPES, Eugénia S. Métodos e técnicas de investigação social. Porto: Areal editores, 2011.

PACHECO, José A. (org.). Políticas educativas: o neoliberalismo em educação. Porto: Porto editora, 2000.

POKEWITZ, Thomas S. Reforma educacional: uma política sociológica, poder e conhecimento em educação. Porto Alegre: Artes Médicas, 1997.

QUITEMBO, Alberto J. A formação de professores e os desafios da educação em Angola: algumas reflexões. In MORGADO, José C.; QUITEMBO, Alberto D. (orgs.). Currículo, avaliação e inovação em Angola: perspectivas e desafios. Benguela: Ondjiri , 2014, pp. 95-127.

SOUSA, Maria J. ; BAPTISTA, Cristina S. Como fažer investigação, dissertações, teses e relatório segundo Bolonha. Lisboa: Pactor, 2011.

TAVARES, Maria A. Professor, curriculo e mudança: a reforma educativa em Angola. Benguela: Ondjiri, 2015.

TRIVIÑOS, Augusto N. Introdução à pesquisa em ciências sociais: a pesquisa qualitativa em educação. São Paulo: Atlas, 2010.

ZABALA, Antoni. A prática educativa: como ensinar. Porto Alegre: Artmed, 1998.

ZAU, Filipe. Do acto educativo ao exercício da cidadania. Luanda: Mayamba, 2012.

Submetido em setembro de 2020

Aprovado em novembro de 2020

\footnotetext{
Informações do autor

Francisco Caloia Alfredo

Instituto Superior Politécnico Independente do Lubango

E-mail: franciscocaloia10@gmail.com

ORCID: https://orcid.org/0000-0002-1570-3679
} 
